\title{
Supporting Information \\ Li Alginate-based Artificial SEI Layer for Stable Lithium Metal Anodes
}

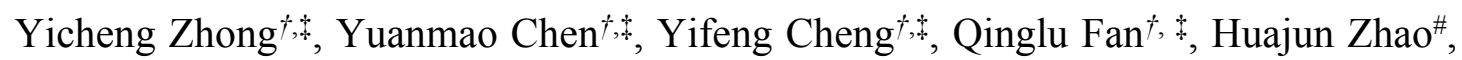
Huaiyu Shao $\#$, Yanqing Lai ${ }^{\perp}$, Zhicong Shi ${ }^{\dagger,}, *, \mathrm{Xi} \mathrm{Ke}^{\dagger, \star *}$ and Zaiping Guo $\$$,*

† School of Materials and Energy, Guangdong University of Technology, Guangzhou, 510006, China

\$ Guangdong Engineering Technology Research Center for New Energy Materials and Devices, Guangzhou, 510006, China

\# Joint Key Laboratory of the Ministry of Education, Institute of Applied Physics and Materials Engineering (IAPME), University of Macau, Avenida da Universidade, Taipa, Macau SAR, China.

${ }^{\perp}$ School of Metallurgy and Environment, Central South University, Changsha, 410083, China

${ }^{\S}$ Institute for Superconducting \& Electronic Materials, School of Mechanical, Materials and Mechatronics Engineering, University of Wollongong, Wollongong, NSW 2522, Australia

* E-mail: zhicong@gdut.edu.cn (Z. Shi), kexi@gdut.edu.cn (X. Ke), zguo@uow.edu.au (Z. Guo) 


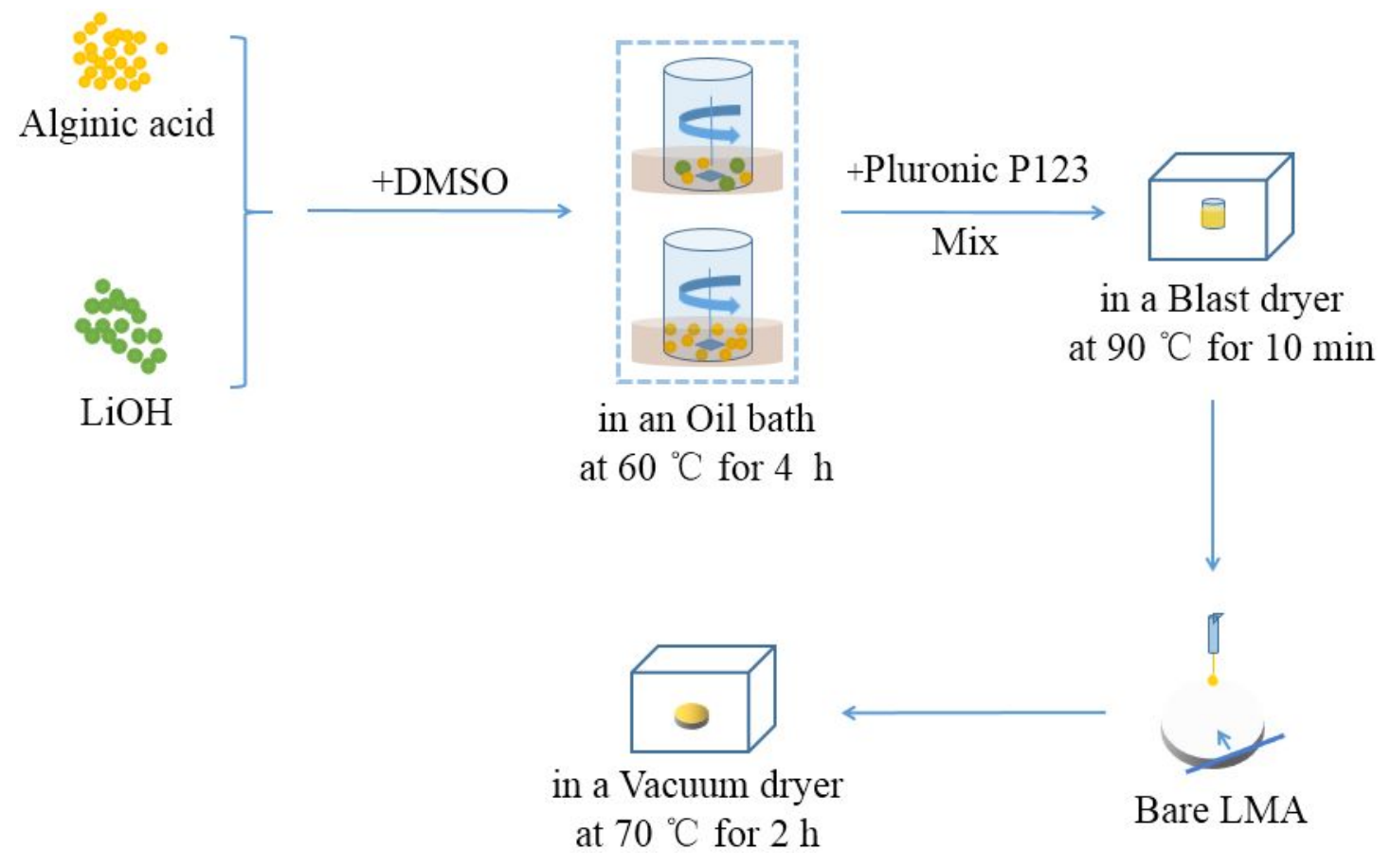

Figure S1. Scheme of fabrication procedure for the ASEI layer-protected LMA.

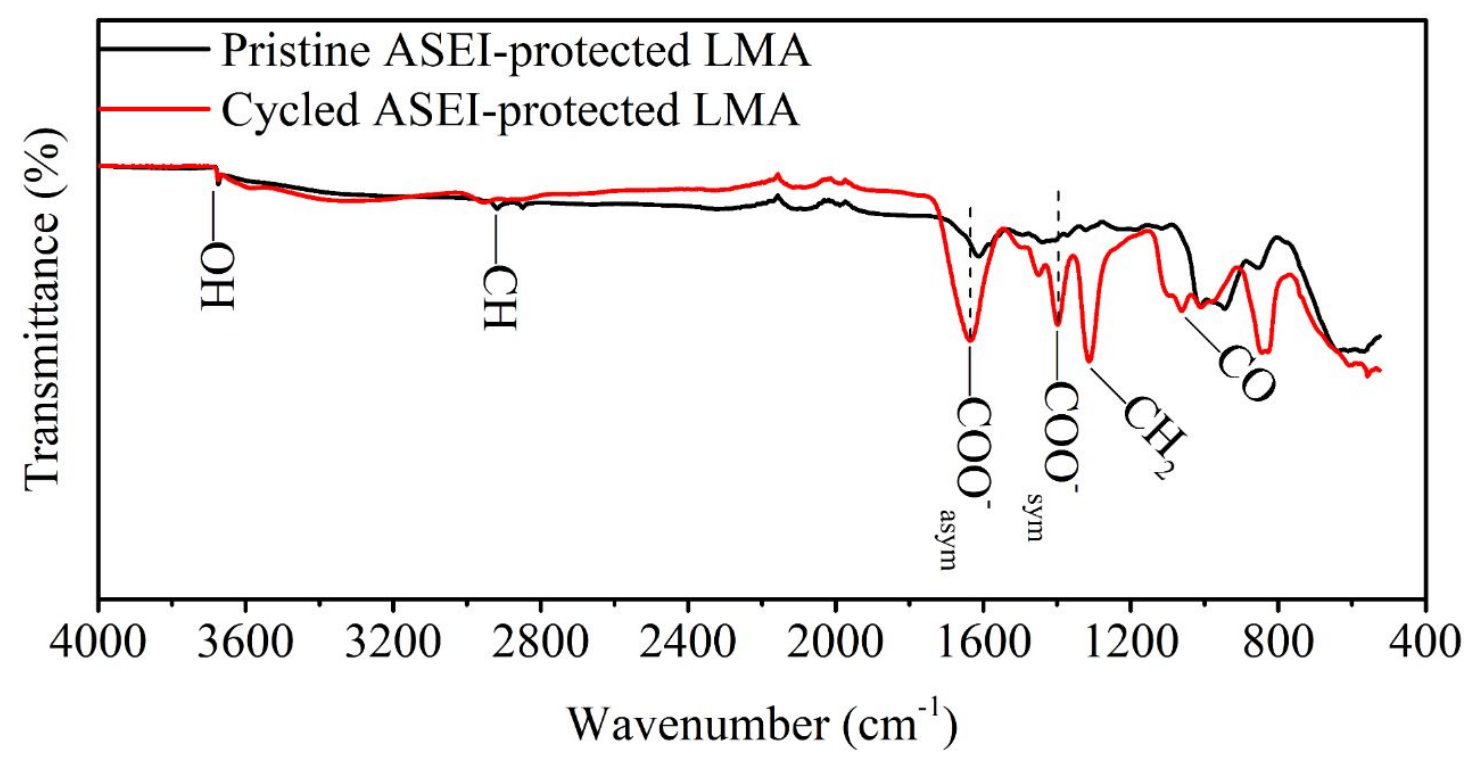

Figure S2. The FTIR absorption spectra of pristine and cycled ASEI layer-protected LMAs. The cycled ASEI layer-protected LMA was derived from a symmetric Li||Li cell with the ASEI layer-protected LMA after cycling for $44 \mathrm{~h}$ at a current density of 1 $\mathrm{mA} \mathrm{cm}{ }^{-2}$ with a capacity of $1 \mathrm{mAh} \mathrm{cm}^{-2}$. 


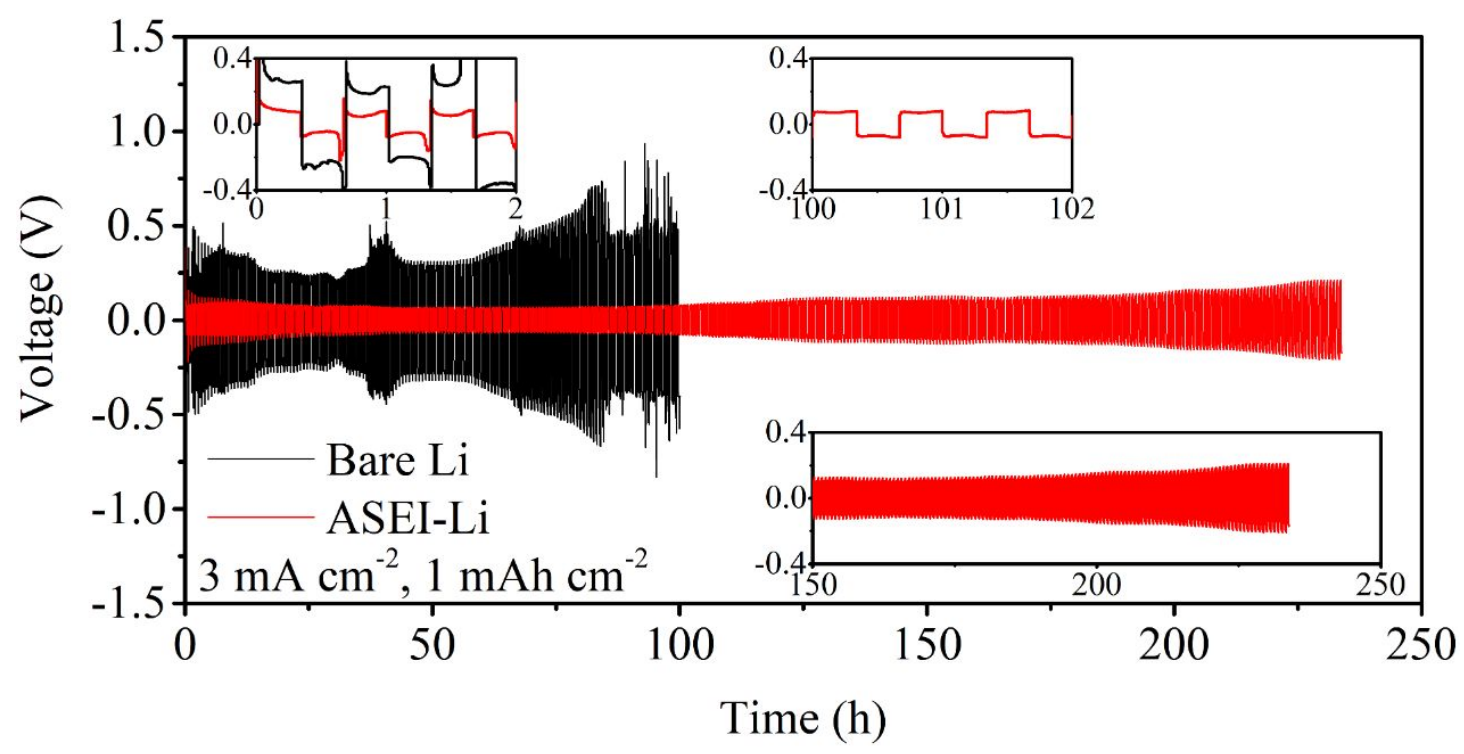

Figure S3. Voltage-time profiles of the Li plating/stripping cycles in the symmetric Li $\|$ Li cells with the ASEI layer-protected LMA and bare LMA, respectively, at a current density of $3 \mathrm{~mA} \mathrm{~cm}^{-2}$ with a capacity of $1 \mathrm{mAh} \mathrm{cm}$.

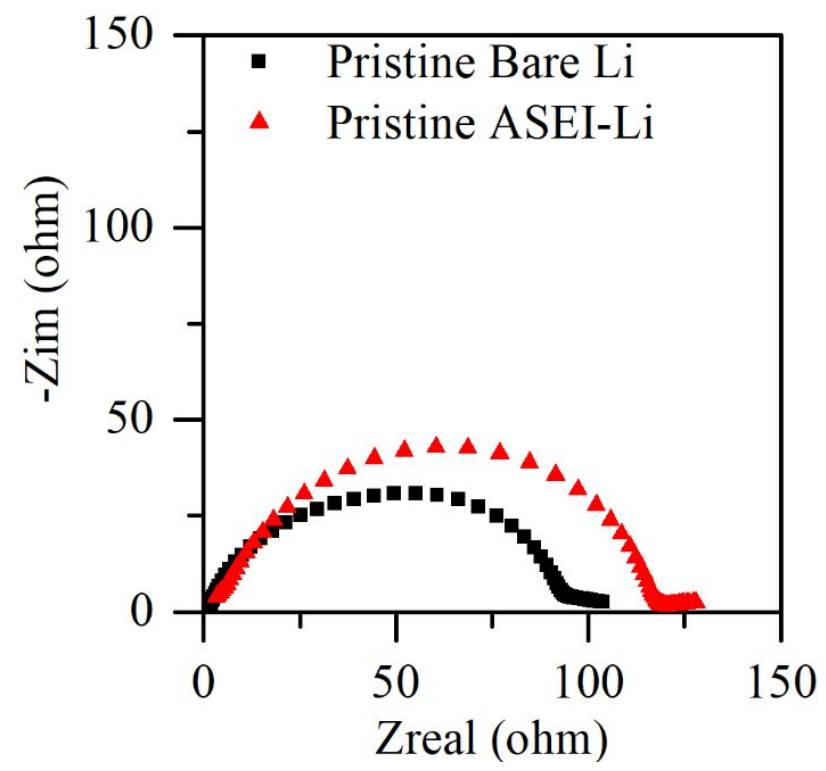

Figure S4. EIS curves of the pristine symmetric Li||Li cells with the bare LMA and the Li alginate-based ASEI layer-protected LMA, respectively. 


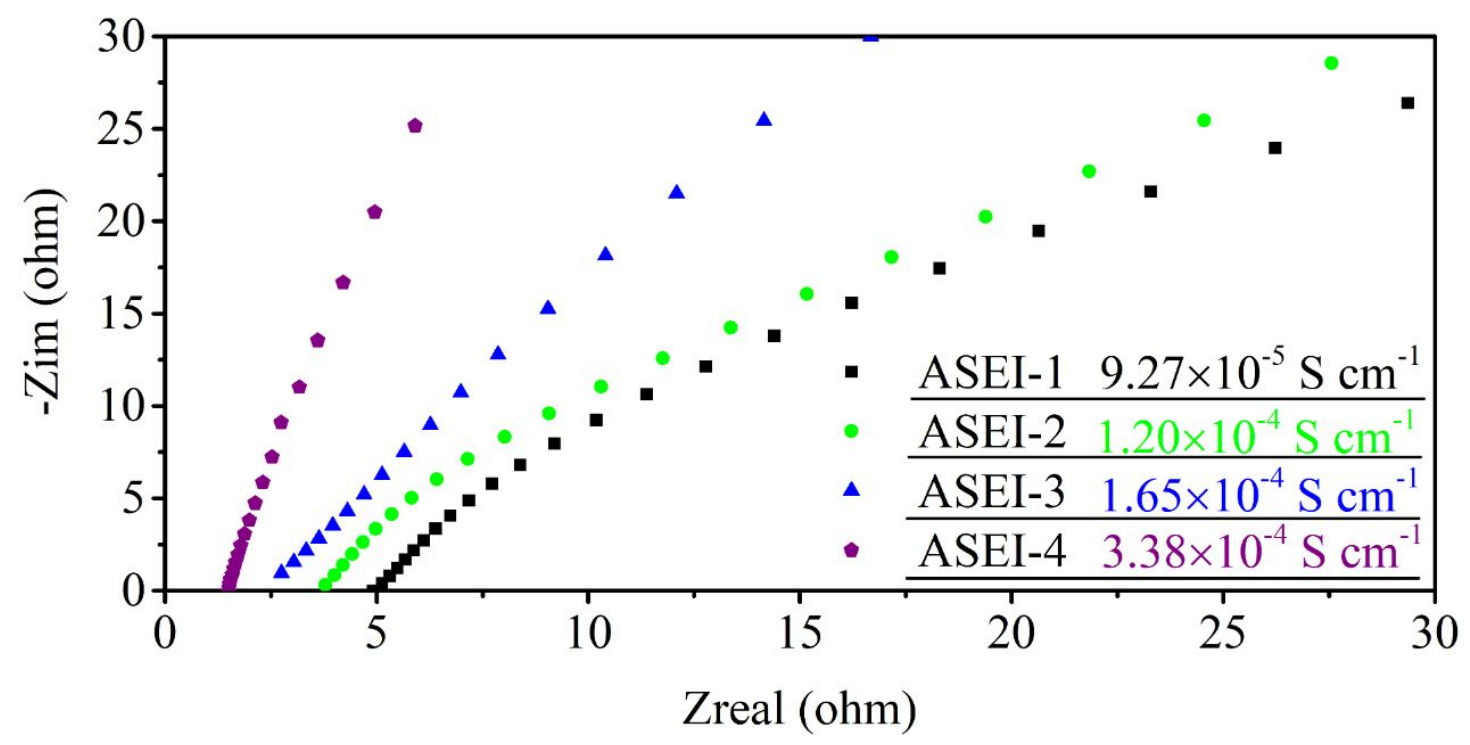

Figure S5. Li ion conductivity tests of the ASEI layers infiltrated by the electrolyte A.

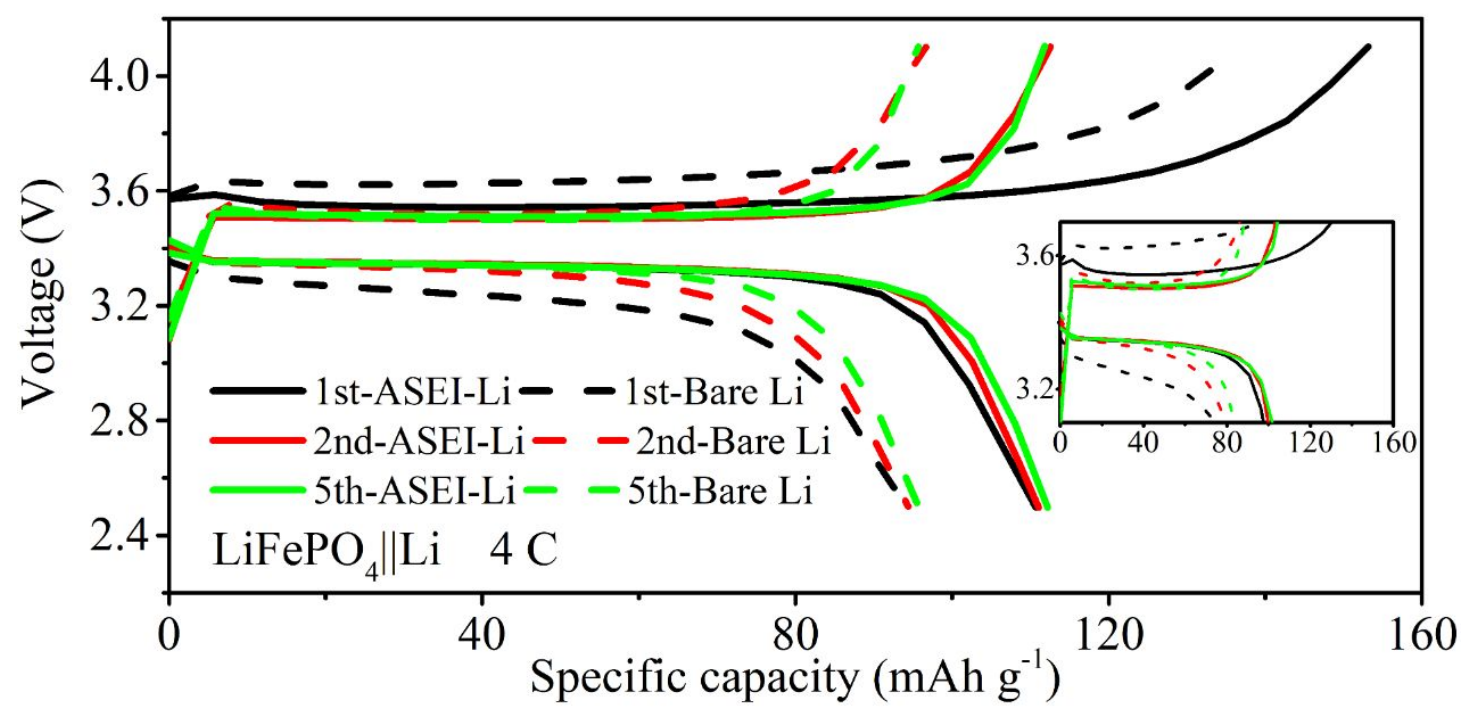

Figure S6. Charge/discharge profiles of the $\mathrm{LiFePO}_{4} \| \mathrm{Li}$ full cells with the ASEI layerprotected LMA and the bare LMA, respectively. Insets: enlarged part of the charge/discharge profiles. 

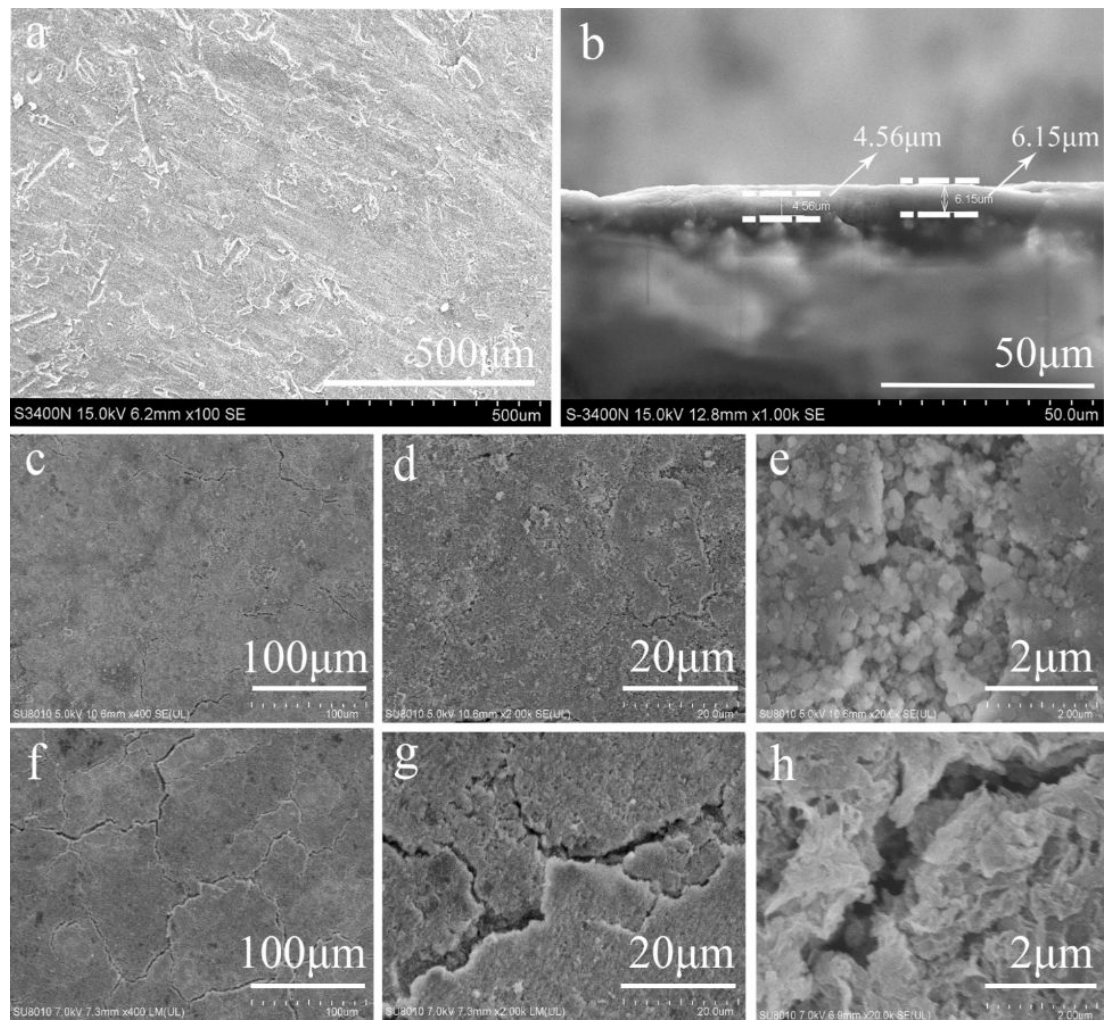

Figure S7. SEM images of the top view (a) and the cross-sectional view (b) for the pristine ASEI layer-protected LMAs. Top-view SEM images with different magnifications of the ASEI layer-protected LMA (c, d, e) and bare LMA (f, g, h) for $\mathrm{LiFePO}_{4} \| \mathrm{Li}$ full cells after 1000 cycles at $5 \mathrm{C}$.

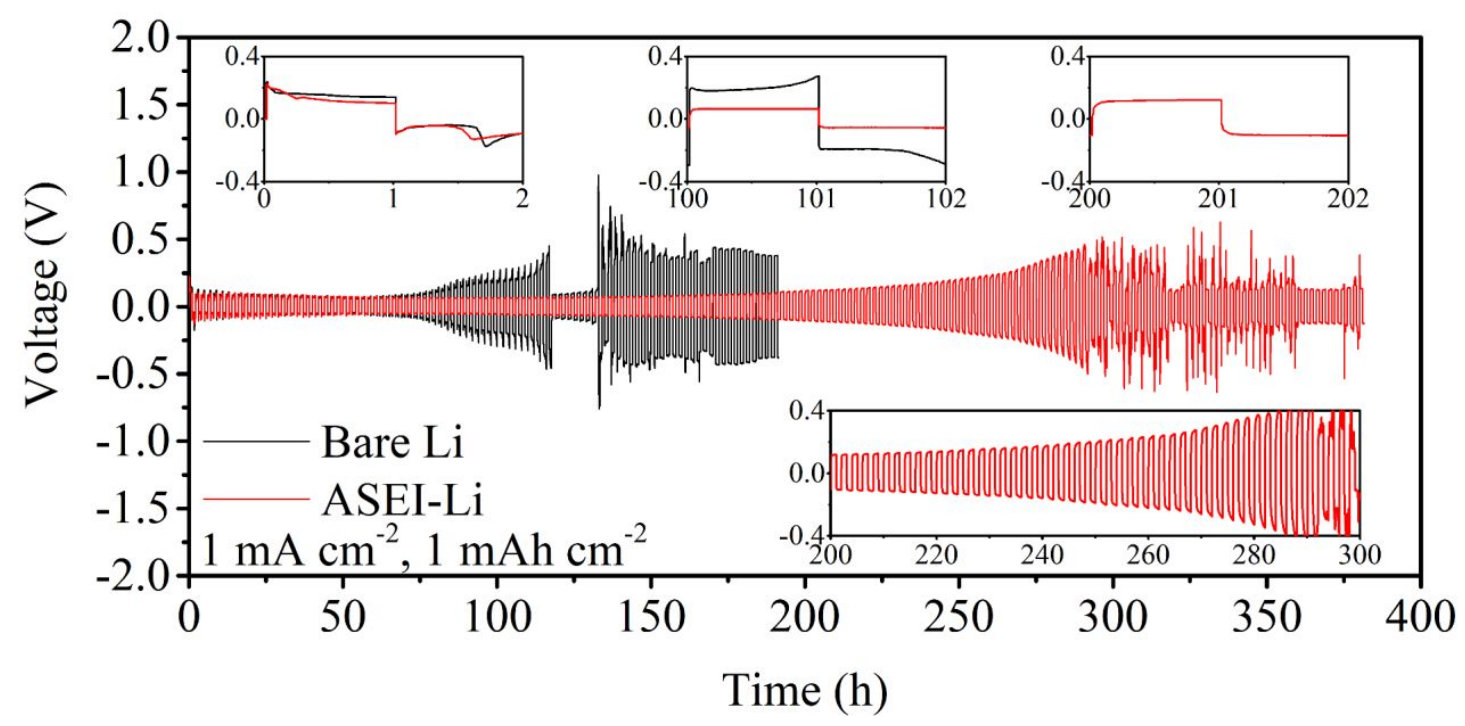

Figure S8. Voltage-time profiles of the Li plating/stripping cycles in the symmetric $\mathrm{Li} \| \mathrm{Li}$ cells at a current density of $1 \mathrm{~mA} \mathrm{~cm}^{-2}$ with a capacity of $1 \mathrm{mAh} \mathrm{cm} \mathrm{cm}^{-2}$. 
a

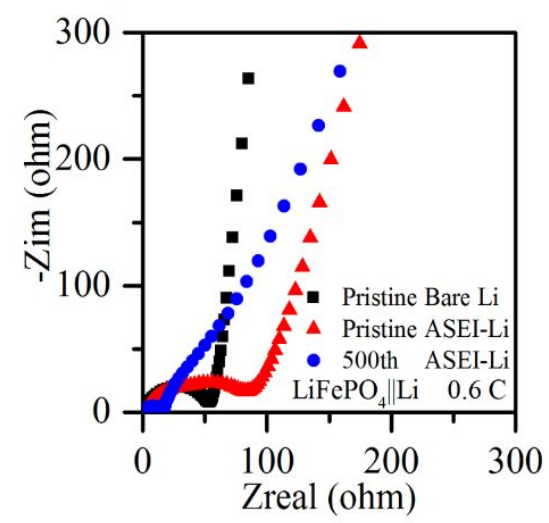

C
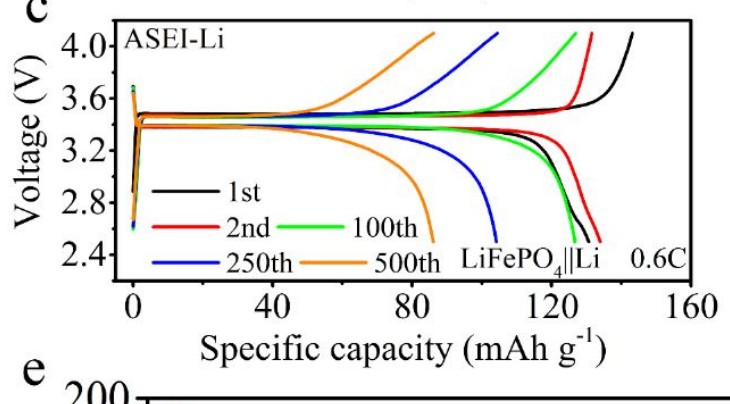

b

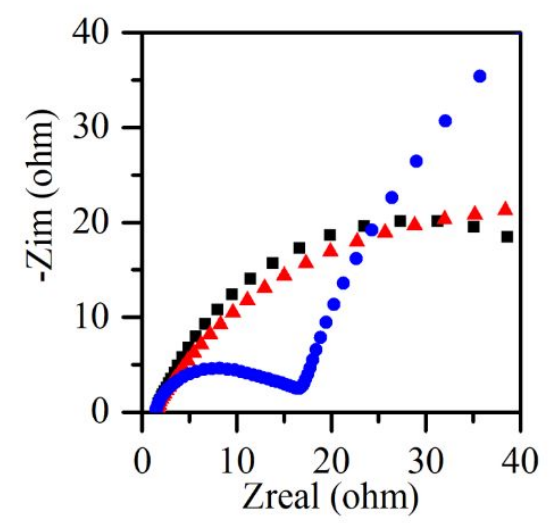

$\mathrm{d}$

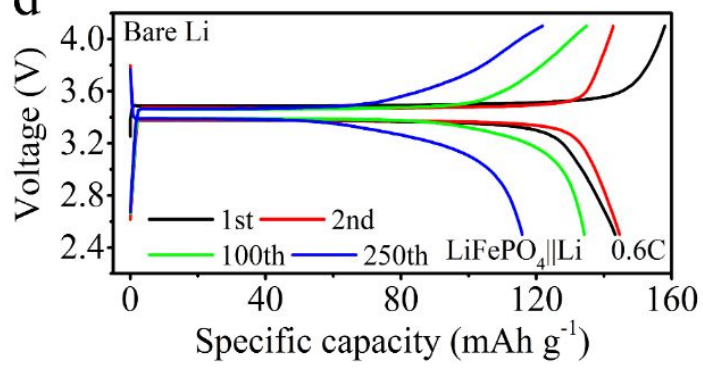

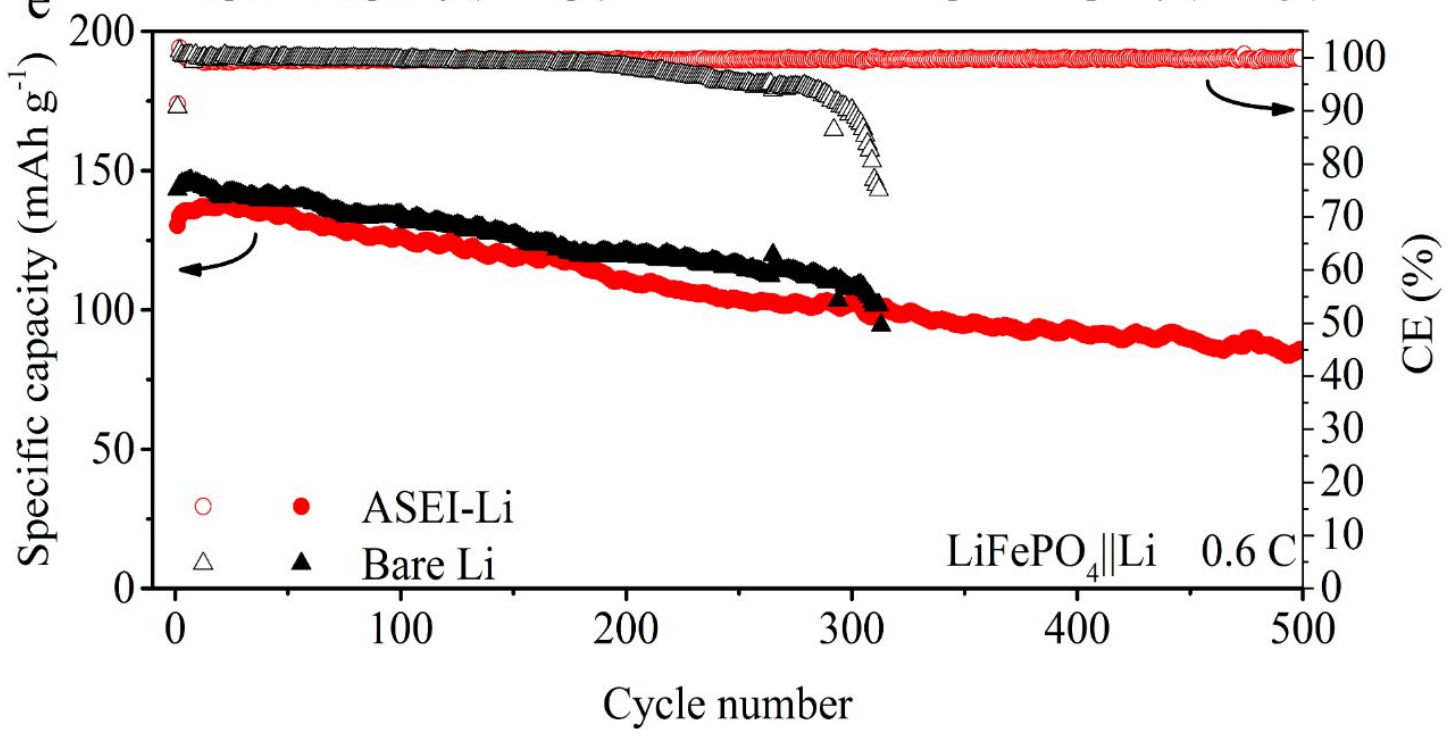

Figure S9. EIS curves $(\mathrm{a}, \mathrm{b})$ of the $\mathrm{LiFePO}_{4}|| \mathrm{Li}$ full cells, charge/discharge profiles of the $\mathrm{LiFePO}_{4} \| \mathrm{Li}$ full cells with the ASEI layer-protected LMA (c) and the bare LMA (d), and the corresponding cycling performance (e) of the $\mathrm{LiFePO}_{4} \| \mathrm{Li}$ full cells at 0.6 C. 
Table S1. Warburg coefficients of the $\mathrm{LiFePO}_{4}|| \mathrm{Li}$ cells with electrolyte B.

\begin{tabular}{ccc}
\hline & ASEI-Li & Bare Li \\
\hline Cycles & $\sigma$ & $\sigma$ \\
0 & 452.97 & 227.91 \\
100 & 39.19 & 60.33 \\
200 & 46.92 & 115.61 \\
300 & 46.04 & \\
400 & 52.05 & \\
500 & 59.08 & \\
600 & 60.12 & \\
700 & 65.21 & \\
800 & 69.60 & \\
900 & 74.34 & \\
1000 & 81.50 & \\
\hline
\end{tabular}

